\title{
A Novel Stacked SIEA Flap for Unilateral Immediate Breast Reconstruction
}

\author{
Eamon C. Francis, BA, BCH, MAO, MCH ${ }^{1} \quad$ Jeffrey Y. Chan, $\mathrm{MD}^{1}$ Alan J. Hussey, MD ${ }^{1}$
}

1 Department of Plastic and Reconstructive Surgery, Galway University Hospital, Galway, Connaught, Ireland

J Reconstr Microsurg Open 2017;2:e49-e51.

Breast reconstruction using a perforator-based autologous flap is increasingly recognized as the preferred technique that provides an aesthetically pleasing restoration of breast form and volume with longevity. Autologous flap reconstruction is widely accepted as the gold standard with deep inferior epigastric artery perforator (DIEP) flap being favored. $^{1}$

When there is insufficient abdominal tissue to recreate a symmetrical contralateral breast shape and volume, stacking flaps using a bipedicled technique has been shown to be an efficacious technique for achieving adequate volume. ${ }^{2}$ Bilateral DIEP flaps are typically stacked for unilateral reconstruction. Alternatively, a single DIEP can be combined with another autologous flap, most commonly the profunda artery perforator (PAP) and superior gluteal artery perforator flaps to achieve the desired volume. ${ }^{3}$

Stacking superficial inferior epigastric artery (SIEA) flaps are sparsely reported in the literature. Malata et al reported a single case over of a Hamdi type 1 bipedicled immediate stacked SIEA over a 40-month period with 112 consecutive flaps, ${ }^{4}$ and Murray et al reported a single case of a delayed stacked SIEA reconstruction over a 5-year period with 18 consecutive unilateral stacked breast reconstructions. ${ }^{5}$

To our knowledge, this is the first reported case of stacked perforator-to-perforator SIEA flap for an immediate unilateral breast reconstruction.

\section{Case History}

We present the case of a 54-year-old woman who had screen-detected high-grade ductal carcinoma in situ. She underwent lumpectomy with subsequent reexcision of a positive radial margin. She declined adjuvant radiotherapy and elected to have an immediate mastectomy and autologous reconstruction.

She had an "E" cup bra, was a nonsmoker, and had no previous abdominal surgeries. She was noted to have a

received

January 16, 2017 accepted after revision March 11, 2017
Address for correspondence Eamon C. Francis, BA, BCH, MAO, $\mathrm{MCH}$, Department of Plastic and Reconstructive Surgery, University College Hospital, Galway, Connaught, Ireland (e-mail: francise@tcd.ie).

moderate pannus and did not wish to use other potential autologous donor sites for reconstruction.

Her mastectomy weight was $690 \mathrm{~g}$. The contralateral left hemiabdomen was raised on the SIEA/SIEV, and the flap weighed $350 \mathrm{~g}$. The left SIEA was anastomosed with the right internal mammary artery (IMA) and left SIEV to the right internal mammary vein (IMV) with a 2.0 -mm coupler. An ontable decision to raise the right hemiabdomen on the SIEA/ SIEV was taken and gave a flap weight of $330 \mathrm{~g}$ (-Fig. 1).

The right SIEA was anastomosed with a noneponymous arterial perforator through the pectoralis major muscle as an end-to-end anastomosis with 9/0 ethilon. The right SIEV was anastomosed with a local vein, which was likely a branch of the IMV proper as an end-to-end with 10/0 ethilon (-Fig. 2). Flap ischemic times were 45 and 50 minutes, respectively. The right flap was completely deepithelized and used as the base and lateral portion of neobreast. The left flap was stacked and used as the skin paddle. This achieved well on table volume and symmetry with the contralateral breast (-Fig. 3).

The patient was discharged well on day 7 and followed up in our outpatient clinic and had an aesthetically pleasing result at 6 weeks (-Fig. 4).

\section{Discussion}

In unilateral breast reconstruction, a double-pedicled stacked flap approach is a viable and useful adjunct with a defect that requires the use of the pannus in its entirety. ${ }^{6}$

The stacked flap is more challenging but can be aided by a safe and logical approach. The stacked approach is more technically demanding than a standard single-pedicle flap. As women seeking unilateral breast reconstruction increasingly request a lifelong autologous solution, our skills must improve to provide the ideal solution.

Folding, rather than dividing double-pedicled flaps has demonstrated good stability and form without fat necrosis in
DOI http://dx.doi.org/ 10.1055/s-0037-1602390. ISSN 2377-0813.
Copyright $\odot 2017$ by Thieme Medical Publishers, Inc., 333 Seventh Avenue, New York, NY 10001, USA Tel: +1(212) 584-4662.

\section{License terms}

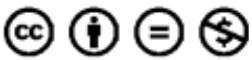




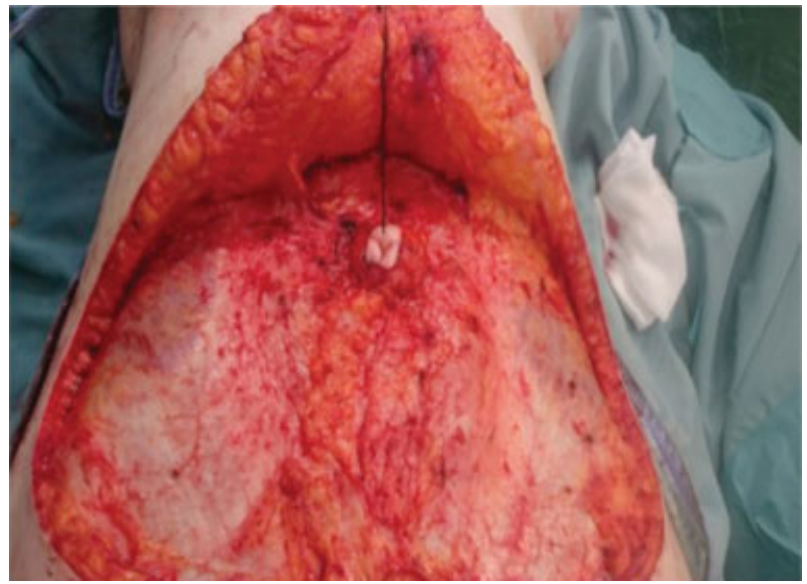

Fig. 1 Preserved anterior rectus sheath.



Fig. 2 Microsurgical anastomoses.

the folded zone. ${ }^{5}$ This contrasts with other series that advocate flap division regarding concerns about developing a zone of hypoperfusion. ${ }^{7}$

The bilateral stacked SIEA flap offers the benefits of a completely autologous reconstruction. The flap harvest is more efficient than that of a deep inferior epigastric artery (DIEA) or PAP flap. There is no secondary wound and no breach in the rectus sheath/muscle reducing the risk of hernia and pain markedly. It provides an equivocal aesthetic outcome seen with other options for stacked autologous reconstruction.

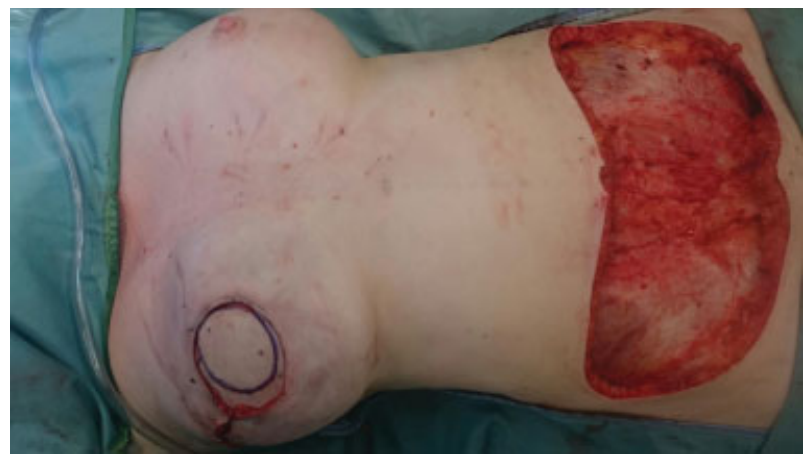

Fig. 3 Stacked superior flap as skin paddle.

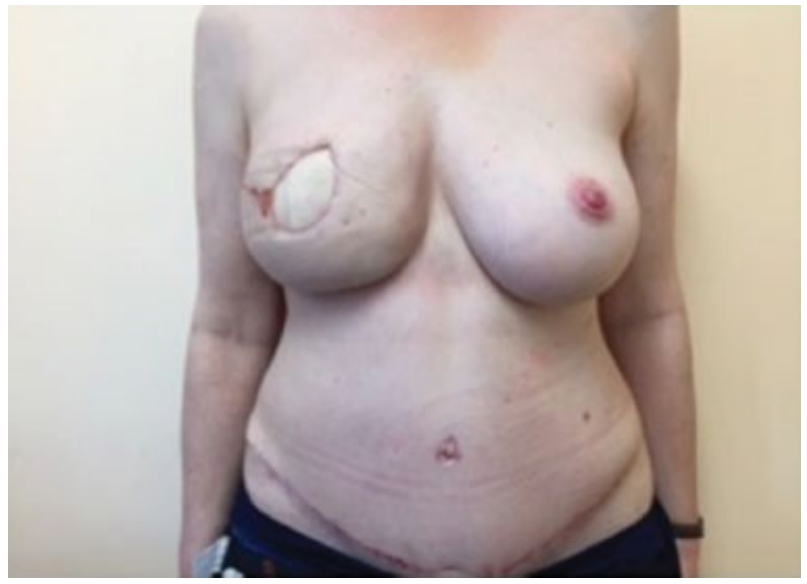

Fig. 4 Postoperative result in outpatients at 6 weeks.

There are two large series of stacked autologous breast tissue reconstructions, the first had a mean operative time of greater than 10 hours $^{8}$ and Allen et al was 7 hours and 20 minutes. ${ }^{3}$ In our case procedure time was 7 hours and 30 minutes.

In our current economic and health climate, the emphasis is consistently placed on an efficient and cost-saving breast reconstruction, while trying to decrease patient morbidity.

The aesthetics created by a SIEA autologous flap reconstruction is quite favorable. ${ }^{9}$ These flaps offer upper-pole fullness often deficient from single abdominal-based flap breast reconstruction. This may potentially eliminate the need for multiple adjunctive sessions of autologous fat grafting to address contour defects postoperatively. ${ }^{10}$

It has also been postulated that the use of two individual flaps for each breast, each slightly smaller in weight than usual, may reduce that burden on venous drainage and arterial perfusion on the pedicle and, thus fat necrosis. ${ }^{10}$ Ultimately this will need to be addressed in a larger series with multiple flap reconstructions.

Limitations of this combination are that vessel caliber can be too small, flap volume is typically less than a DIEA, potential flap loss is increased, and certain patients may not have a superficial system to harvest.

\section{Conclusion}

The stacked SIEA flaps should be considered as an efficient and viable option for stacking instead of more established combinations to provide the necessary volume for breast reconstruction when there are suitable pedicles for safe microsurgical transfer.

\section{References}

1 Nahabedian MY, Dooley W, Singh N, Manson PN. Contour abnormalities of the abdomen after breast reconstruction with abdominal flaps: the role of muscle preservation. Plast Reconstr Surg 2002;109(01):91-101 
2 Rabey NG, Erel E, Malata CM. Double-pedicled abdominal free flap using an entirely new microvascular combination of DIEP and SIEA vascular pedicles for unilateral breast reconstruction: a novel addition to the Hamdi classification. Plast Reconstr Surg 2012;130(05):767e-769e

3 Mayo JL, Allen RJ, Sadeghi A. Four-flap breast reconstruction: bilateral stacked DIEP and PAP flaps. Plast Reconstr Surg Glob Open 2015;3(05):e383. Doi: 10.1097/GOX.0000000000000353

4 Malata CM, Rabey NG. Decision making in double-pedicled DIEP and SIEA abdominal free flap breast reconstructions: an algorithmic approach and comprehensive classification. Front Surg 2015;2:49. Doi: 10.3389/fsurg.2015.00049

5 Murray A, Wasiak J, Rozen WM, Ferris S, Grinsell D. Stacked abdominal flap for unilateral breast reconstruction. J Reconstr Microsurg 2015;31(03):179-186

6 Hamdi M, Khuthaila DK, Van Landuyt K, Roche N, Monstrey S. Double-pedicle abdominal perforator free flaps for unilateral breast reconstruction: new horizons in microsurgical tissue transfer to the breast. J Plast Reconstr Aesthet Surg 2007; 60(08):904-912, discussion 913-914

7 DellaCroce FJ, Sullivan SK, Trahan C. Stacked deep inferior epigastric perforator flap breast reconstruction: a review of 110 flaps in 55 cases over 3 years. Plast Reconstr Surg 2011;127(03): 1093-1099

8 DellaCroce FJ, Sullivan SK, Trahan C, Jenkins CE. Body lift perforator flap breast reconstruction: a review of 100 flaps in 25 cases. Plast Reconstr Surg 2012;129(03):551-561

9 Chevray PM. Breast reconstruction with superficial inferior epigastric artery flaps: a prospective comparison with TRAM and DIEP flaps. Plast Reconstr Surg 2004;114(05):1077-1083, discussion 1084-1085

10 Choi M, Small K, Levovitz C, Lee C, Fadl A, Karp NS. The volumetric analysis of fat graft survival in breast reconstruction. Plast Reconstr Surg 2013;131(02):185-191 